S table 1. Three-item self-reported adherence scale.

\title{
Item 1:
}

In the last 30 days, on how many days did you miss at least one dose of any of your HIV medicines?

Range 0-30

\section{Item 2:}

In the last 30 days, how good a job did you do at taking your HIV medicines in the way that you were supposed to? Range "very poor" to "excellent" (1-6)

\section{Item 3:}

In the last 30 days how often did you take your HIV medicines in the way that you were supposed to? Range "never" to "always" (1-6)

Combined three-item scale:

An aggregated score based on re-coding each item with equal weighting to create a score ranging from 0 to 100 (100 represents the best possible self-reported adherence)
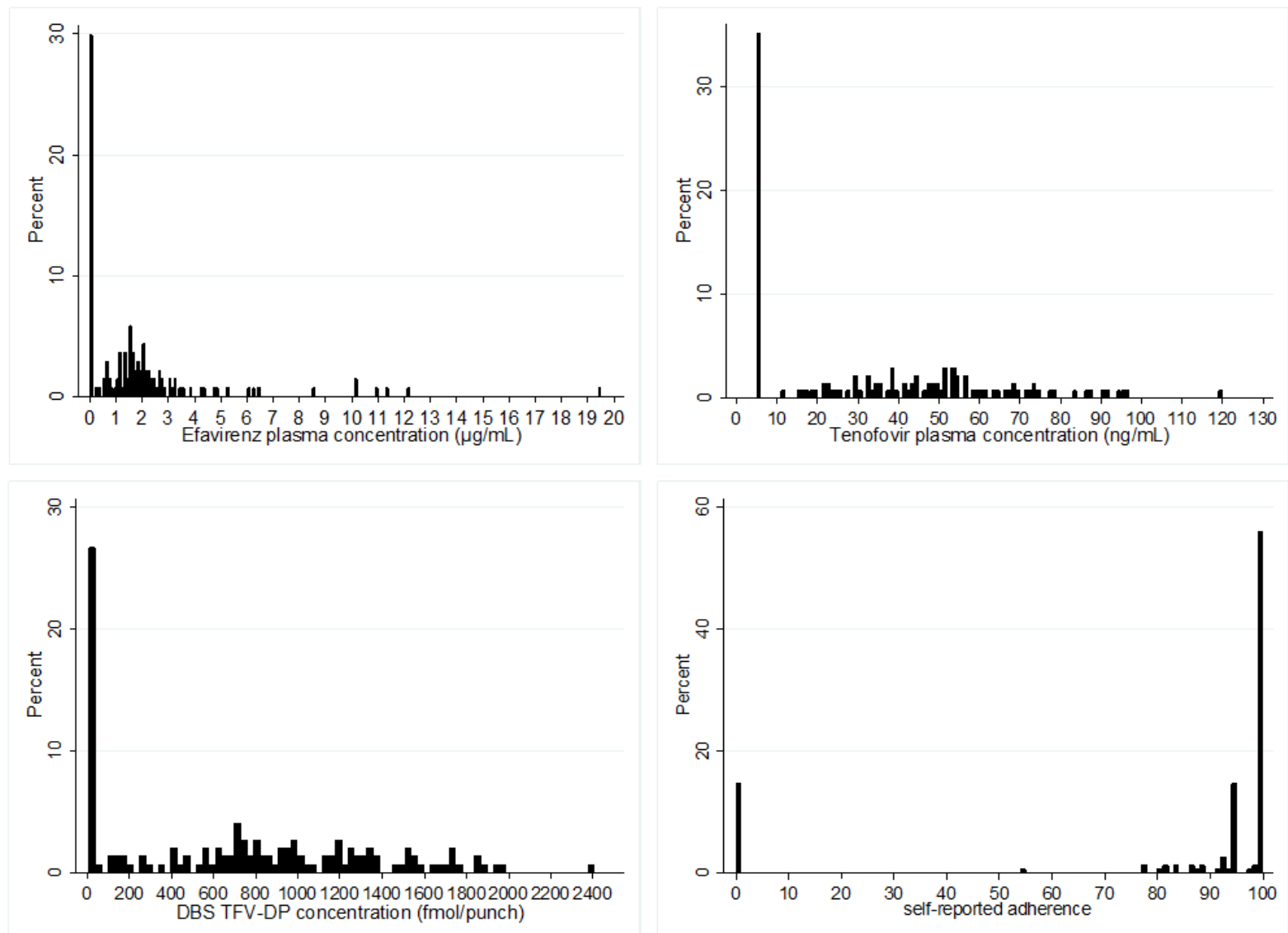

S figure 1. Histograms of a) plasma efavirenz, b) plasma tenofovir, c) tenofovir-diphosphate (TFV-DP) concentrations in dried blood spots (DBS), d) self-reported adherence in the past 30 days (three-item scale score). 
Plasma EFV and TFV vs DBS TFV-DP in PLWH: Supplementary Digital Content
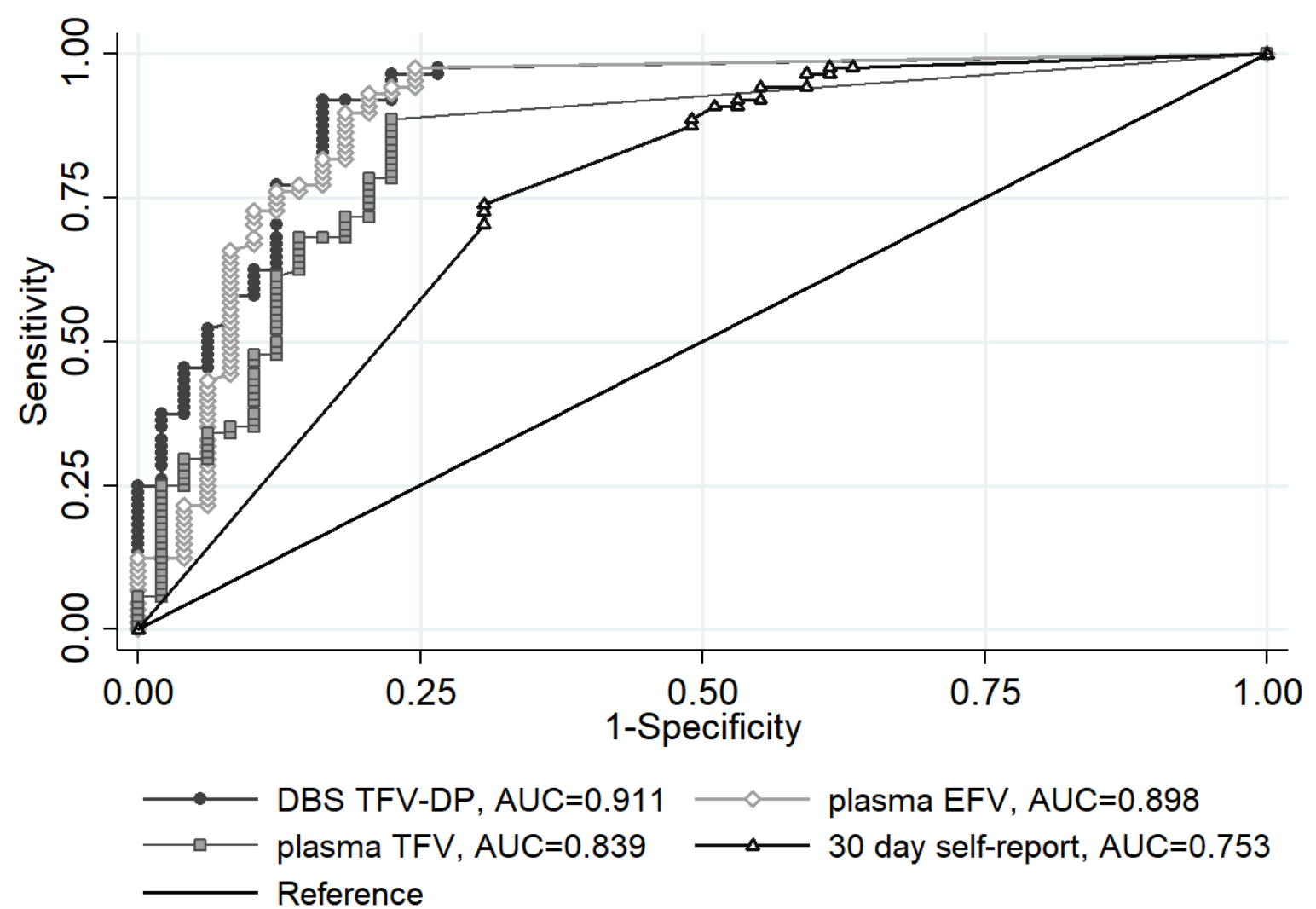

$S$ figure 2. Unadjusted area under the receiver operating characteristics (ROC) curves of DBS TFV-DP (grey), plasma EFV (green), plasma TFV (maroon), and self-reported adherence (blue) to predict viral suppression; $\mathrm{n}=137$. 
Plasma EFV and TFV vs DBS TFV-DP in PLWH: Supplementary Digital Content

S table 2. Characteristics of DBS TFV-DP thresholds restricted to women who report taking ART in the last 30 days ( $\mathrm{n}=87$ ). Odds ratios (OR) predicting viral load $<50,<400$ and $<1000$ copies $/ \mathrm{mL}$ are presented.

\begin{tabular}{|c|c|c|c|c|}
\hline $\begin{array}{l}\text { TFV-DP threshold } \\
\text { (approximate doses per } \\
\text { week }^{1} \text { ) }\end{array}$ & $<350(<2)$ & $350-699(2-3)$ & $700-1249(4-6)$ & $\geq 1250$ (7) \\
\hline Total number of women & 27 & 19 & 41 & 30 \\
\hline $\begin{array}{l}\text { Median viral load } \log _{10} \\
\text { copies/mL (IQR) }\end{array}$ & $3.7(2.5-4.6)$ & $1.3(1.3-1.3)$ & $1.3(1.3-1.3)$ & $1.3(1.3-1.3)$ \\
\hline $\begin{array}{l}\text { Median viral load } \\
\text { copies/mL (IQR) }\end{array}$ & $4884(282-38325)$ & $20(20-20)$ & $20(20-20)$ & $20(20-20)$ \\
\hline \multicolumn{5}{|c|}{ Viral load <50 copies/mL } \\
\hline $\begin{array}{l}\text { Viral load <50 } \\
\text { copies/mL, n }(\%)\end{array}$ & $5(19)$ & $16(84)$ & $36(88)$ & $29(97)$ \\
\hline OR $(95 \%$ CI $)$ & Ref & $23(5-113)$ & $32(8-122)$ & $128(14-1172)$ \\
\hline aOR2 (95\% CI) & Ref & $28(5-142)$ & $34(8-139)$ & $135(14-1268)$ \\
\hline \multicolumn{5}{|c|}{ Viral load <400 copies/mL } \\
\hline $\begin{array}{l}\text { Viral load <400 } \\
\text { copies/mL, n }(\%)\end{array}$ & $7(26)$ & $17(89)$ & $39(95)$ & $30(100)$ \\
\hline OR $(95 \%$ CI $)$ & Ref & $24(4-133)$ & $56(11-293)$ & Omitted \\
\hline $\mathbf{a O R}^{2}(95 \% \mathrm{CI})$ & Ref & $35(5-230)$ & $74(12-462)$ & Omitted \\
\hline \multicolumn{5}{|c|}{ Viral load <1000 copies/mL } \\
\hline $\begin{array}{l}\text { Viral load <1000 } \\
\text { copies/mL, } \mathbf{n}(\%)\end{array}$ & $8(30)$ & $17(89)$ & $39(95)$ & $30(100)$ \\
\hline OR $(95 \% \mathrm{CI})$ & Ref & $20(4-109)$ & $46(9-240)$ & Omitted \\
\hline $\mathbf{a O R}^{2}(95 \% \mathrm{CI})$ & Ref & $29(5-178)$ & $59(10-360)$ & Omitted \\
\hline
\end{tabular}

${ }^{1}$ As previously described by Castillo-Mancilla et al (CID, 2018)

${ }^{2}$ Adjusted for age and duration on ART 
Plasma EFV and TFV vs DBS TFV-DP in PLWH: Supplementary Digital Content

$\mathrm{S}$ table 3. Univariable logistic regression models predicting viral load $<50,<400$ and $<1000$ copies/mL among 137 women.

\begin{tabular}{llll}
\hline & $\begin{array}{l}\text { Viral load <50 } \\
\text { copies/mL } \\
\text { OR 95\% CI }\end{array}$ & $\begin{array}{l}\text { Viral load <400 } \\
\text { copies/mL } \\
\text { OR 95\% CI }\end{array}$ & $\begin{array}{l}\text { Viral load <1000 } \\
\text { copies/mL } \\
\text { OR 95\% CI }\end{array}$ \\
\hline Increasing years of age & $1.10(1.02-1.18)$ & $1.11(1.03-1.20)$ & $1.08(1.00-1.17)$ \\
\hline Increasing years on ART & $1.38(0.28-6.75)$ & $1.76(0.33-9.26)$ & $2.30(0.43-12.40)$ \\
\hline Increasing BMI $\left(\mathbf{k g} / \mathbf{m}^{\mathbf{2}}\right)$ & $1.05(1.00-1.11)$ & $1.04(0.99-1.09)$ & $1.04(0.99-1.10)$ \\
\hline $\begin{array}{l}\text { Increasing creatinine clearance } \\
\mathbf{m L} / \mathbf{m i n} / \mathbf{1 . 7 3 m ^ { 2 }}(\mathbf{n}=\mathbf{7 4})\end{array}$ & $0.98(0.94-1.03)$ & $0.97(0.92-1.02)$ & $0.97(0.92-1.02)$ \\
\hline
\end{tabular}

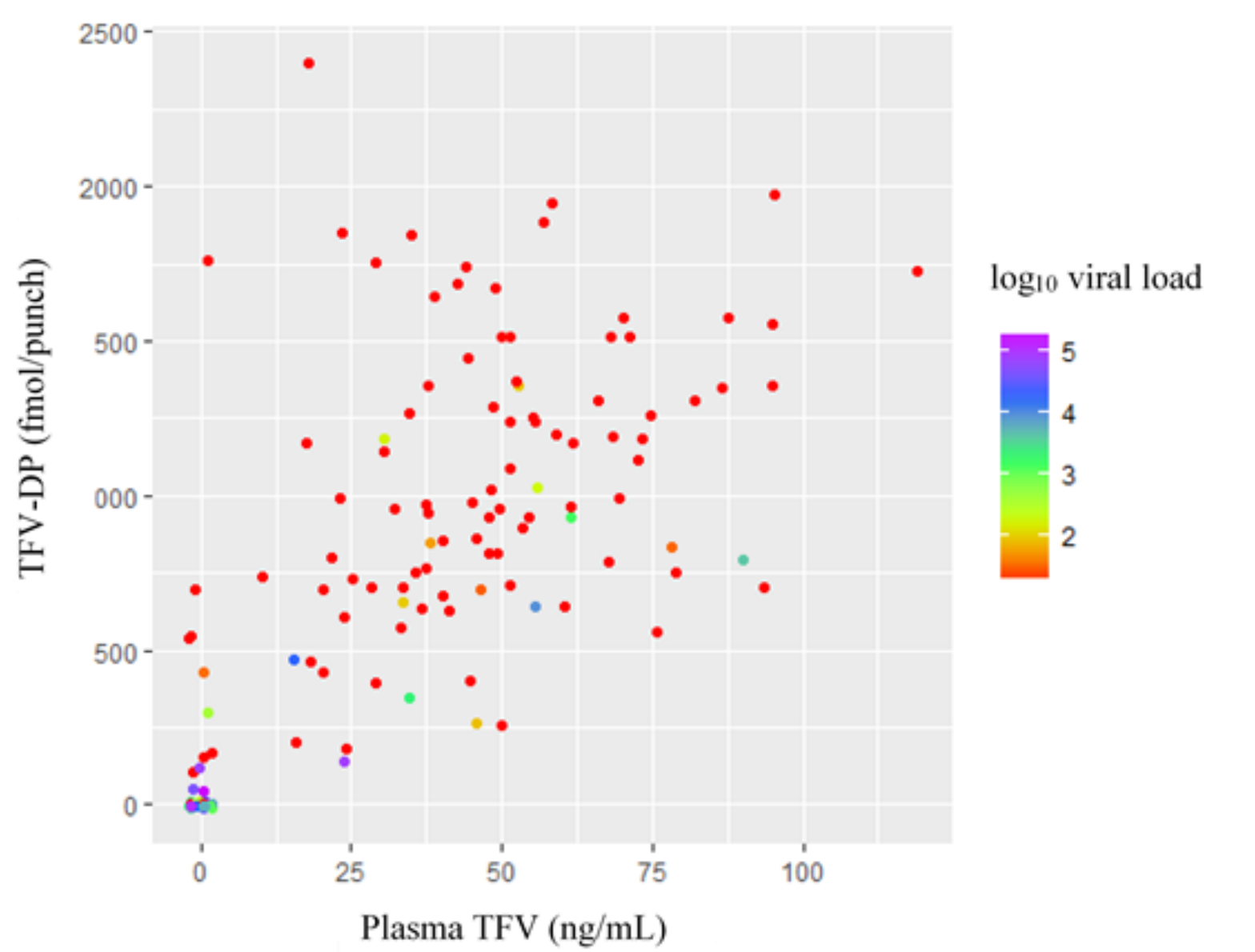

S figure 3. Scatter plot of tenofovir-diphosphate (TFV-DP) in DBS and plasma tenofovir (TFV) concentrations. 
Plasma EFV and TFV vs DBS TFV-DP in PLWH: Supplementary Digital Content

S table 4. Women with detectable plasma tenofovir (TFV) and efavirenz (EFV) concentrations but very low tenofovir-diphosphate concentration in dried blood spots (DBS TFV-DP).

\begin{tabular}{cllll}
\hline Patient & $\begin{array}{l}\text { Viral load } \\
\text { (copies/mL) }\end{array}$ & $\begin{array}{l}\text { DBS TFV-DP } \\
\text { (fmol/punch) }\end{array}$ & $\begin{array}{l}\text { Plasma TFV } \\
(\mathbf{n g} / \mathbf{m L})\end{array}$ & $\begin{array}{l}\text { Plasma EFV } \\
(\mathbf{\mu g} / \mathbf{m L})\end{array}$ \\
\hline $\mathbf{1}$ & 20 & 178 & 25.2 & 1.16 \\
$\mathbf{2}$ & 20 & 209 & 15.1 & 2.04 \\
$\mathbf{3}$ & 87 & 270 & 47.5 & 1.12 \\
$\mathbf{4}$ & 88741 & 136 & 22.6 & 0.54 \\
\hline
\end{tabular}

